\title{
The relationship of multiple aspects of stigma and personal contact with someone hospitalized for mental illness, in a nationally representative sample
}

\author{
Jennifer E. Boyd $\cdot$ Emerald P. Katz $\cdot$ \\ Bruce G. Link · Jo C. Phelan
}

Received: 1 December 2008/Accepted: 23 September 2009/Published online: 13 October 2009

(C) The Author(s) 2009. This article is published with open access at Springerlink.com

\begin{abstract}
The stigma of mental illness has been shown to be affected by personal contact with mental illness and by a belief in the genetic heritability of mental illness. We use data from a nationally representative survey to test whether the relationship of stigma with contact remains after taking into account the effects of genetic beliefs and other background characteristics. Contact was defined as a history of psychiatric hospitalization among respondents themselves, their family members, or their friends. Respondents answered questions about a vignette character with a mental illness. We found that respondents with contact felt less anger and blame toward the character, thought that the character had a more serious problem, and would want less social distance from the character, including both casual and intimate aspects of social distance. Respondents with contact were not significantly different from the general population in the degree to which they expressed sympathy, thought the problem would last a lifetime, or wanted
\end{abstract}

\section{J. E. Boyd ( $\square)$}

Department of Psychiatry, University of California/San

Francisco and San Francisco VA Medical Center,

4150 Clement Street (116A), San Francisco, CA 94121, USA

e-mail: jennifer.boyd@ucsf.edu

E. P. Katz

Psychosocial Rehabilitation and Recovery Center,

San Francisco VA Medical Center, San Francisco, CA, USA

B. G. Link

Departments of Epidemiology and Sociomedical Sciences,

Mailman School of Public Health, Columbia University and

New York State Psychiatric Institute, New York, NY, USA

J. C. Phelan

Department of Sociomedical Sciences,

Mailman School of Public Health, Columbia University,

New York, NY, USA to restrict reproduction. Thus, contact is associated with having a less ostracizing, critical attitude toward a stranger with mental illness. The results underscore the importance of this experienced group as a resource in fighting stigma in society. Since many people who have had a psychiatric hospitalization have not told their friends or family members about it, this lower-stigma group could be enlarged.

Keywords Stigma $\cdot$ Mental illness - Survey ·

Personal experience $\cdot$ Contact

\section{Introduction}

The stigma of mental illness continues to be strong and pervasive in our society, and to have detrimental effects on people with mental illness. Overall, stigma impedes recovery from mental illness and, thus, represents a tremendous burden on people with mental illness and on society in general $[17,19,25,26]$. More specifically, the stigmatizing label of mental illness has the objective external effects of discrimination in housing, employment, and insurance coverage $[12,14,16,18]$. Those marked as mentally ill are underemployed and earn less income than those with the same psychiatric challenges who have not received the label [1]. Stigma also has subjective internal effects, such as eroding self-esteem and mood over time and contributing to social withdrawal and reduced trust in others due to the anticipation of negative responses from others [1, 12, 17, 24]. Internalized stigma also makes people with mental illness reluctant to seek or remain in treatment $[10,25]$. Numerous studies have shown that stigma causes an increase in the social distance between people with mental illness and other members of society $[1,4,5,11,21,28]$. Social distance is a measure of 
ostracism that includes, for example, reluctance to make friends with someone, or to allow someone to join the family, solely on the basis of their mental illness [3]. In short, stigma prevents people with mental illness from taking part fully in society.

Of course, many people do have friends or family members with mental illness or have experienced mental illness themselves. Is this group less likely to exhibit stigma when they encounter someone with mental illness? Allport [2] proposed that cooperative interaction with members of a negatively evaluated group results in increased liking for those members and generalizes to more positive attitudes toward the group, suggesting that friends and family members should have more positive attitudes than the public at large. The phenomenon of in-group bias and its cascade of prejudicial attitudes [7,27] suggests that people with mental illness should also have less negative attitudes than the public at large. However, there are also reasons to expect that these groups would not have particularly favorable attitudes. Self-stigmatizing processes might lead persons with mental health problems to internalize negative societal attitudes toward themselves and others with mental illness [8]. Similarly, the process of distancing [26] oneself from a negatively evaluated group might also negate the development of more positive attitudes among people with mental illness. Further, associative stigma $[22,29]$ experienced by family and friends could lead this group to distance themselves from mental illness as well, again leading to a prediction that this group will have attitudes that are no more positive than those of the general public.

Several studies have found that previous contact is associated with more positive responses toward people with mental illness, including more positive emotional responses, reduced stereotypes, and a desire for less social distance $[6,11,15,21]$. Based on these findings, we expect contact and in-group bias processes to predominate and predict that people who have friends or family members with mental illness or have experienced mental illness themselves will express more positive attitudes toward people with mental illness.

Here, we extend the existing literature on contact and stigma with a vignette-based study that has two particular strengths. First, we employ a random-digit-dial sample that used screening questions to oversample respondents who had experienced a psychiatric hospitalization in their immediate family. Thus, the study is almost unique in assessing the association between contact and attitudes in a nationally representative sample in the United States. Second, we are able to examine many facets of stigma, ranging from emotional aspects, such as blame, anger, and sympathy, to cognitive aspects, such as perceived persistence and perceived seriousness, to more behavioral aspects, such as social distance and reproductive restriction, in a single study, so that direct comparisons between different aspects of stigma can be made. We focus our examination on a very direct personal level of contact, that is, whether respondents themselves, their family, or their friends have been hospitalized for mental illness. Finally, we are able to consider the role of contact within the context of a comprehensive array of relevant background characteristics.

Social contact and in-group biases are thought to have quite broad and general effects on attitudes toward social groups. We therefore, hypothesize that people with contact will exhibit less stigma in a very broad sense. Thus, we predict that people in our contact group will say that the character with mental illness in the vignette is less to blame for their illness, that they feel less anger and more sympathy toward the character, that they think the character's problem is less serious and chronic, that they desire less social distance from the character, and that they are less interested in restricting the character's reproduction.

In secondary analyses, we also test if the results differ depending on whether the vignette character is described as having schizophrenia or major depression. We also assess, whether results differ if we exclude those who hospitalized themselves from the "contact" group. The remaining group (family and friends of a hospitalized person) is important for two reasons. The friends-and-family group is the one that can test the contact hypothesis. Second, the group of people in society who know they have a friend or family member who have been hospitalized could be enlarged if more people who were hospitalized disclosed this fact to their friends and family. If attitudes are more positive among this group than among members of the public with no such contact, it suggests that greater disclosure of mental-health problems might improve public attitudes toward mental illness.

Our broader consideration of the consequences of stigma is a novel feature in research on the effect of contact. These analyses allow us to examine whether the relation of contact and stigma is general or whether it is limited to certain aspects of stigma.

\section{Methods}

\section{Sample}

The target population comprised of people aged 18 and above, living in households with telephones, in the continental United States. The sampling frame was derived from a list-assisted, random-digit-dialed (RDD) telephone frame. A respondent was randomly selected from among all adults in the household. Telephone interviews were conducted 
with 1,416 respondents between June 2002 and March 2003. Interviews were conducted in English, Spanish, Mandarin, and Cantonese and averaged $20 \mathrm{~min}$. The sample was stratified to oversample Puerto Ricans, Chinese Americans, and people with a family history of psychiatric hospitalization. Using estimation procedures of the Council of American Survey Research Organizations (1982), the response rate was $62 \%$.

\section{Comparison with the census}

To evaluate sample selection bias, we compared the weighted analysis sample with 2000 census data for gender, educational attainment, household income, and age. Correspondence with the census is good in terms of age, but the sample overrepresents women and people with higher SES. Participants' gender and age, as well as other sociodemographic characteristics, are controlled in the main analyses.

\section{Weighting}

Results are weighted to take into account poststratification adjustment to national counts by race/ethnicity and differential selection probabilities based on race/ethnicity and family history of psychiatric hospitalization. To calculate statistical tests, we used SUDAAN [23] which estimates standard errors for complex survey designs.

\section{Vignette}

All participants were randomly assigned to one of two vignette experiments. Each experiment included some vignettes that described psychiatric disorders and some that described physical disorders. The 911 participants included in the present analysis responded to a vignette about a person with schizophrenia or major depressive disorder. The vignettes from the two experiments were quite similar in describing psychiatric symptomatology and hospitalization experience but varied in their description of the vignette character's demographic and social background characteristics (e.g., age, education), which were also randomly assigned. Data from both of these vignette experiments were combined in this study to maximize the number of participants with mental-illness contact. Variations in response due to differences in the details of vignettes 1 and 2 were statistically controlled by including vignette number as a covariate in the main analysis. There were 684 participants who received vignette 1 (343 schizophrenia and 341 major depressive disorder), and 227 participants who received vignette 2 (123 schizophrenia and 104 major depressive disorder). The vignette character's race/ethnicity was matched to that of the respondent, with a suitable name given to the character. An example of vignette 1 is shown below:

Imagine a person named Anne. She is a single, 25year-old white woman. Since graduating from high school, Anne has been steadily employed and makes a decent living. Usually, Anne gets along well with her family and coworkers. She enjoys reading and going out with friends. About a year ago, Anne started thinking that people around her were spying on her and trying to hurt her. She became convinced that people could hear what she was thinking. She also heard voices when no one else was around. Sometimes she even thought people on TV were sending messages especially to her. After living this way for about six months, Anne was admitted to a psychiatric hospital and was told that she had an illness called "schizophrenia." She was treated in the hospital for two weeks and was then released. She has been out of the hospital for six months now and is doing OK. Now, let me tell you something about what caused Anne's problem. When she was in the hospital, an expert in genetics said that Anne's problem was due to genetic factors. In other words, her problem had a very strong genetic or hereditary component.

The study from which the data were derived [20] focused on the effect of genetic attribution on stigma, but the present study is not focused on that issue, so we statistically controlled for the experimentally manipulated genetic attribution in the analyses.

\section{Measures}

Contact We coded evidence of experience with acute mental illness on a 4-point scale. Respondents who said that they had been hospitalized for a mental illness themselves were given a score of 3 , those with a family member (parents, children, or sibling) hospitalized were scored 2, those with a friend hospitalized were scored 1, and those with none of the above was scored 0 . Those who fit into more than one category were given the higher score. In the weighted sample, $16(1.8 \%)$ participants scored 3, 64 (7.1\%) scored 2, 380 (42.6\%) scored 1, and $432(48.4 \%)$ scored 0 . We also conducted analyses using a dichotomous version of this variable (family, friend, or self hospitalized versus none) and the results (not shown but available) were similar. We present results from the 4-point scale because of the increased statistical power.

Blame was assessed with the item "Anne is to blame for her condition." This was scored on a scale from 1 (strongly disagree) to 4 (strongly agree), and had a mean of 1.36 $(\mathrm{SD}=0.72)$. 
Anger was assessed with the item "When you think of Anne, you feel anger towards her." This was scored on a scale from 1 (strongly disagree) to 4 (strongly agree), and had a mean of $1.18(\mathrm{SD}=0.49)$.

Sympathy was assessed with the item "When you think of Anne, you feel sympathy." This was scored on a scale from 1 (strongly disagree) to 4 (strongly agree), and had a mean of $3.23(\mathrm{SD}=0.87)$.

Perceived persistence was measured with the item "In your opinion, Anne will probably continue to have problems like the ones I described for her whole life." This was scored on a scale from 1 (strongly disagree) to 4 (strongly agree), and had a mean of $2.71(\mathrm{SD}=0.97)$.

Perceived seriousness was measured with the item "How serious would you consider her problem to be? This was scored on a scale from 1 (not serious at all) to 4 (very serious), and had a mean of $3.40(\mathrm{SD}=0.65)$.

Social distance was measured with a 5-item scale (Cronbach's alpha $=0.89)$. The scale composed of two parts. "Intimate" social distance was measured with three items (alpha $=0.94$ ): "How would you feel about having Anne date/marry/have a baby with one of your children?" ("very positive," "somewhat positive," "somewhat negative," and "very negative"). The total score ranged from 1 to 4 , with 4 indicating greater social distance. The mean for intimate social distance was $2.46(\mathrm{SD}=0.86)$. "Casual" social distance was measured with two items $($ alpha $=0.69)$ : "How willing would you be to make friends with Anne?" ("definitely willing," "probably willing," "probably unwilling," and "definitely unwilling"); and "How willing would you be to have Anne start working closely with you on a job?" ("definitely willing," "probably willing," "probably unwilling," and "definitely unwilling"). The total score ranged from 1 to 4 , with 4 indicating greater social distance. The mean for casual social distance was $1.77(\mathrm{SD}=0.62)$. The total social distance score combined the intimate and casual scores and ranged from 1 to 4 , with 4 representing greater social distance. The mean for total social distance was 2.18 $(\mathrm{SD}=0.69)$. For half of the respondents to vignette 1 , social distance questions were asked about the character's sibling rather than the character.

Reproductive restriction was assessed with two items $($ alpha $=0.67)$ : "Anne should not get married-that is, she should stay single" and "Anne should not have any children of her own - that is, she should remain childless." These were scored on a scale from 1 (strongly disagree) to 4 (strongly agree), and had a mean of $1.65(\mathrm{SD}=0.77)$.

Covariates A comprehensive set of controls was used. The same set of covariates was used in the present study as in the original study from which the data were derived [20]. Thus, the analyses controlled for gender, age, education, household income, ethnicity/race, political conservatism, eugenic concerns, and belief in the importance of genetic factors in mental illness. In addition, the present study controlled for vignette type ( 1 or 2 ), vignette diagnosis (schizophrenia or depression), and genetic attribution (whether the character's illness was said to be caused by genetics or not). Descriptive statistics and more details about the operationalization of these covariates are shown in Table 1.

Table 1 Sample and vignette characteristics used as covariates, in weighted analysis sample $(N=911)$

\begin{tabular}{|c|c|}
\hline & $\%$ or Mean $(\mathrm{SD})$ \\
\hline Female & 63.7 \\
\hline Age & $48.3(16.7)$ \\
\hline \multicolumn{2}{|l|}{ Highest education level completed } \\
\hline Eighth grade or less & 3.3 \\
\hline Some high school & 7.2 \\
\hline High school graduate (or GED) & 29.4 \\
\hline Trade or technical school & 2.9 \\
\hline Some college (or associate's degree) & 23.8 \\
\hline College graduate & 21.9 \\
\hline Postgraduate work/advanced degree & 11.5 \\
\hline \multicolumn{2}{|l|}{ Household income in 2001} \\
\hline Under $\$ 20,000$ & 19.3 \\
\hline$\$ 20,000$ up to $\$ 40,000$ & 25.8 \\
\hline$\$ 40,000$ up to $\$ 60,000$ & 21.9 \\
\hline$\$ 60,000$ up to $\$ 80,000$ & 13.2 \\
\hline$\$ 80,000$ or more & 19.9 \\
\hline African-American & 13.6 \\
\hline Asian-American & 3.1 \\
\hline Hispanic & 9.9 \\
\hline Other non-White race/ethnicity & 2.5 \\
\hline \multicolumn{2}{|l|}{ Political conservatism } \\
\hline Very liberal & 7.2 \\
\hline Somewhat liberal & 16.8 \\
\hline Moderate & 31.3 \\
\hline Somewhat conservative & 31.7 \\
\hline Very conservative & 13.0 \\
\hline Eugenic concerns & $2.4(0.79)$ \\
\hline \multicolumn{2}{|c|}{ Belief in importance of genetic factors in mental illness } \\
\hline Not important at all & 4.1 \\
\hline Not very important & 10.8 \\
\hline Somewhat important & 49.4 \\
\hline Very important & 35.7 \\
\hline Vignette type 2 & 25.2 \\
\hline Vignette diagnosis schizophrenia & 51.1 \\
\hline \multicolumn{2}{|l|}{ Genetic attribution } \\
\hline Not genetic & 36.7 \\
\hline Partly genetic & 29.7 \\
\hline Strongly genetic & 33.6 \\
\hline
\end{tabular}

$N$ is the unweighted number of observations used in the analysis 
Table 2 Association of contact with aspects of stigma

\begin{tabular}{llll}
\hline Dependent variable & $\begin{array}{l}\text { Beta for mental } \\
\text { illness experience }\end{array}$ & $\begin{array}{l}\text { Standard } \\
\text { error }\end{array}$ & $N$ \\
\hline Blame & $-0.12^{* * *}$ & 0.03 & 676 \\
Anger & $-0.04^{*}$ & 0.02 & 680 \\
Sympathy & 0.06 & 0.05 & 673 \\
Perceived persistence & 0.06 & 0.05 & 663 \\
Perceived seriousness & $0.08^{*}$ & 0.04 & 676 \\
Social distance, total & $-0.10^{* *}$ & 0.03 & 665 \\
Social distance, casual & $-0.08^{* *}$ & 0.03 & 681 \\
Social distance, intimate & $-0.12^{* *}$ & 0.04 & 655 \\
Reproductive restriction & -0.05 & 0.04 & 677 \\
\hline
\end{tabular}

$N$ is the unweighted number of observations used in the analysis. Educational attainment, family income, age, gender, ethnicity (dummy variables for African-American, Asian-American, Hispanic, and "other"), political conservatism, eugenic concerns, belief in the importance of genetic factors in mental illness, vignette type, vignette diagnosis, and genetic attribution are controlled. Differences in sample size are due to missing data on dependent variables

$* p<0.05 ; * * p<0.01$; *** $p<0.0001$

\section{Results}

Controlling for respondents' education, income, age, gender, ethnicity, political views, genetic beliefs, and vignette type, we found that more contact was associated with less blame for the mental illness toward the vignette character, less anger toward the character, and less social distance from the character, including both casual and intimate aspects of social distance (Table 2). Respondents with more contact were not significantly different from the general population in the degree to which they expressed sympathy for the character, thought the character would have the problem for a lifetime, or would want to restrict the character's reproduction (Table 2). Contrary to our hypothesis, those with greater contact judged the character's problem to be more serious (Table 2). Thus, we found differences pertaining to numerous aspects of stigma, from emotional (less blame and less anger), to cognitive (greater perceived seriousness, which was opposite to the expected direction), to behavioral (less social distance). The results were not the same across all aspects of stigma tested. To explore the statistically significant results further, we tabulated the mean scores broken down by type of contact, for each of the variables that had been statistically significant in the controlled analyses (Table 3). For the emotional aspects of stigma (blame and anger), there is no clear gradient across all four degrees of intensity of contact. For perceived seriousness, those with family or friends hospitalized perceived a greater degree of seriousness, while those who had been hospitalized themselves perceived a lesser degree of seriousness (this difference between those who had been hospitalized themselves and others was not statistically significant in controlled analyses, as shown below). For all three social distance variables, there was an apparent gradient showing reduced social distance across increasingly greater degrees of contact.

In addition to the above analyses, testing our primary set of hypotheses, we also undertook some additional analyses to test secondary questions. To test whether the effects were the same for vignettes featuring major depression versus schizophrenia, we added the interaction between vignette diagnosis and contact to the models. The interaction was not statistically significant $(p>0.05)$ for any of the aspects of stigma. To test whether the effects held true among the subgroup of those who would be affected by disclosures of mental illness (family members and friends), we ran the main models again excluding those with personal hospitalization experience. In this reduced sample, all the results were the same (beta for blame $=-0.19$, $\mathrm{SE}=0.05, p<0.001, N=654$; beta for sympathy 0.08 , $\mathrm{SE}=0.07, p=0.30, N=652$; beta for perceived persistence $=0.14, \mathrm{SE}=0.08, p=0.08, N=642$; beta for perceived seriousness $=0.13, \quad \mathrm{SE}=0.05, \quad p<0.05$, $N=654$; beta for social distance, total $=-0.13$. $\mathrm{SE}=0.06, p<0.05, N=643$; beta for social distance,

Table 3 Variation of blame, anger, perceived seriousness, and social distance according to contact with mental illness (mean, standard deviation, and $N$ in the weighted sample)

\begin{tabular}{|c|c|c|c|c|c|c|c|c|}
\hline & \multicolumn{2}{|c|}{ None hospitalized } & \multicolumn{2}{|c|}{ Friend hospitalized } & \multicolumn{2}{|c|}{ Family hospitalized } & \multicolumn{2}{|c|}{ Self hospitalized } \\
\hline & Mean (SD) & $N$ & Mean (SD) & $N$ & Mean (SD) & $N$ & Mean (SD) & $N$ \\
\hline Blame & $1.51(0.83)$ & 426 & $1.23(0.54)$ & 374 & $1.17(0.54)$ & 64 & $1.19(0.58)$ & 16 \\
\hline Anger & $1.25(0.59)$ & 431 & $1.11(0.39)$ & 378 & $1.09(0.30)$ & 64 & $1.13(0.34)$ & 16 \\
\hline Perceived seriousness & $3.34(0.69)$ & 427 & $3.45(0.59)$ & 374 & $3.52(0.67)$ & 62 & $3.26(0.84)$ & 16 \\
\hline Social distance, total & $2.25(0.68)$ & 412 & $2.12(0.72)$ & 362 & $2.09(0.62)$ & 62 & $1.90(0.60)$ & 16 \\
\hline Social distance, casual & $1.85(0.61)$ & 429 & $1.70(0.64)$ & 379 & $1.69(0.55)$ & 64 & $1.53(0.51)$ & 16 \\
\hline Social distance, intimate & $2.53(0.86)$ & 404 & $2.40(0.88)$ & 361 & $2.36(0.80)$ & 62 & $2.14(0.75)$ & 15 \\
\hline
\end{tabular}

$N$ s vary across items due to missing values 
casual $=-0.11, \mathrm{SE}=0.05, p<0.05, N=659$; beta for social distance, intimate $=-0.15, \mathrm{SE}=0.07, p<0.05$, $N=634$; beta for reproductive restriction $=-0.07$, $\mathrm{SE}=0.06, p=0.17, N=655$ ), except that the effect for anger was no longer statistically significant (beta for anger $=-0.06, \mathrm{SE}=0.04, p=0.12, N=658$ ). As an attempt to further examine whether the effect of contact was especially strong among the small number of those who had been hospitalized themselves, we ran the same controlled analyses again using a dummy variable comparing those with personal hospitalization experience to all others, and we found no statistically significant differences (details not shown but available).

\section{Discussion}

This investigation allowed us to examine the relationship of personal contact with mental illness and a wide variety of aspects of stigma. Although all of the indicators were self-report, they reflected behavioral, emotional, and cognitive aspects of stigma. The results indicated that having personal contact with mental illness is associated with having a less ostracizing, less critical attitude toward a stranger with mental illness. This was seen behaviorally in terms of less desire for social distance and emotionally in terms of less blame and anger directed toward the vignette character. This more accepting attitude was present at the same time as a greater cognitive awareness of the seriousness of the character's problem. Contact was not significantly associated with more sympathy, more hopefulness about the prognosis, or a reduced desire to restrict reproduction. This suggests that people with contact have a sober view of the problem: they take it very seriously but still have a more respectful, welcoming attitude toward others with mental illness.

Results do not suggest a clear gradation of stigma with increasing intensity of contact across all the statistically significant aspects of stigma examined, nor do controlled analyses detect an extra reduction in stigma among those with personal hospitalization experience as compared to all other groups combined. Thus, the most parsimonious interpretation for our results is simply that contact with mental illness is associated with reduced stigma. There does seem to be a gradation in social distance across degrees of contact. Future studies would be needed to investigate these issues in more detail.

Other authors, such as Angermeyer et al. [5], have organized variables like our dependent variables according to the reasoning of the stigma process, postulating that negative ideas can translate into negative attitudes, which can translate into negative behavioral intentions (e.g., social distance). Our central question focused on contact and its effects on multiple domains of stigma and we did find evidence that contact is related to each of these three areas (cognitive ideas, emotional attitudes, and behavioral intentions) specified by Angermeyer. Thus, the combination of our findings and Angemeyer's conceptualization raises a critical questions for future research-at which stage (ideas, attitudes, or behavior intentions) is contact most important? Does contact have powerful effects on ideas, which then determine attitudes which in turn influence behavioral intentions? Or does contact have direct and independent effects at each stage. Our work sets the stage for future research to investigate important questions like these.

Our results show that people who have had the experience of contact with someone who has been hospitalized are less stigmatizing in terms of harboring less blame and anger and desiring less social distance when they encounter others with mental illness. These results agree with previous research showing that contact is associated with decreases in negative emotions and desire for social distance $[1,5,11,21]$. Our results also supported the idea of in-group bias $[2,7,27]$, such that those with previous contact with mental illness in a significant other (or in themselves) will have more positive attitudes than the public at large when they encounter others with mental illness.

The results underscore the importance of this experienced "contact" group as a resource in fighting stigma in society. Moreover, since many people who have had a psychiatric hospitalization have not told their friends or family members about it, this lower-stigma group could be enlarged. Our results held true among those who may have found out about the hospitalization through disclosure (everyone except those who were hospitalized themselves). In other words, almost all of the main findings held true when those who had been hospitalized themselves were removed from the analyses, which supports the idea that increased disclosure of hospitalization experiences to family and friends could increase acceptance in the population. Our data focused on hospitalization, but of course there is an even larger group who have experienced only outpatient mental health care. The issue of mental illness is closer to home than what society as a whole may think. One in four US adults experience mental health disorder within a given year, many have families, and one in 17 lives with serious mental illness, such as schizophrenia and major depression as depicted in our vignettes [13]. Mental illness is clearly not a rare condition; however, those experiencing illness are typically aware of the societal stigma and discrimination they will encounter-an awareness often shown, for example, as a reluctance to seek or stay in treatment $[9,10,25]$. Results from the present study provide evidence that those who have had experience with 
psychiatric hospitalization themselves or know family members or friends who have been hospitalized possess a more egalitarian, welcoming attitude, making them viable advocates for dispelling the myths associated with the mentally ill. The lower-stigma group in our study has had direct personal contact with mental illness as a consumer, relative, or friend, supporting Allport's contact hypothesis, where more positive attitudes are formed toward stigmatized groups upon increased contact [2]. The stigma that induces people to maintain secrecy about their mental illness also limits the prospect for inaccurate stereotypes to be countered through personal interaction.

Therefore, we believe that there would be less stigma in society if more of those who had been hospitalized or have been in mental health treatment simply disclosed this fact to others. Once more people realize that they are already socially intimate with people with mental illness, they may seek less social distance when they encounter others with mental illness. Our results also reinforce anecdotal impressions that advocacy organizations, such as NAMI, which is composed mainly of family members of people with mental illness, are likely to promote an anti-stigma point of view.

\section{Limitations}

One limitation of our study is that we cannot determine if those who have experience with mental illness as either a consumer, friend, or relative who report less stigmatizing views held these views before the encounter. Because stigma is associated with reluctance to use mental health services, it is possible that those with lower stigma would be more likely to seek hospitalization or encourage their family or friends to do so, and would, thus, be more likely to show up in our analyses as having contact with someone who had been hospitalized. We do show that those with contact have less stigmatizing views toward newly encountered others with mental illness. We also have no data regarding the quality of contact with friends or relatives with mental illness. Thus, our data do not speak to the specific aspects of the relationships or experiences that are associated with reduced stigma. Furthermore, we did not have a large enough sample to be able to examine the three types of contact (self, family member, and friend) separately with a high degree of statistical power. There was only $1.8 \%$ of the weighted sample with a personal experience of hospitalization, which limited our statistical power in analyses of those in that category versus all others. Similarly, sample size did not allow us to split the social distance data between respondents who were asked about the vignette character and those who were asked about the character's sibling. Still, we found differences between those with contact and the general population in their social distance preferences generalized across these two targets. Furthermore, we have no way of testing whether those with personal hospitalization experience or other forms of contact with mental illness were more or less likely to respond to the survey. We were also limited by defining contact with mental illness as knowing someone who had been hospitalized, which represents just a fraction of people with mental illness.

\section{Recommendations for future research}

Future studies should examine the effect of contact using a wider definition of contact, and a longitudinal design to allow for causal analyses and a larger sample so that the relationship between stigma and the type and extent of contact can be analyzed more thoroughly. Additionally, as mentioned above, future studies might usefully examine whether contact has effects at different stages of the stigma process (ideas, attitudes, intentions, and behaviors) as suggested by Angermeyer. Finally, future studies might also focus more directly on those with personal experience of mental illness.

\section{Conclusion}

Our study examined the relationship between stigma and contact with mental illness using a nationally representative sample, a wide range of aspects of stigma, and analyses that controlled for a variety of differences between respondents. Analyses revealed that respondents who have had experience with psychiatric hospitalization themselves or know family members or friends who have been hospitalized have a more respectful, welcoming attitude toward others with mental illness, in terms of less blame, anger, and social distance. This is despite the fact that they view mental illness as a more serious problem. This type of soberly egalitarian regard grounded in experience would provide the basis for secure connections as they encounter others with mental illness. The community integration so essential to the recovery process is built upon connections like these. People with mental illness and their friends and relatives represent a natural anti-stigma force in society. This group could be enlarged if more people with mental illness "came out of the closet" about it to their friends and relatives. There may be personal risks in doing so, such as attracting stigma, which must be considered carefully, and weighed against potential personal benefits, such as the relief of not having a secret and feeling better understood by others. Aside from the shorter-term individual-level effects of increased disclosure, our results indicate that there would be a longterm benefit to society. 
Open Access This article is distributed under the terms of the Creative Commons Attribution Noncommercial License which permits any noncommercial use, distribution, and reproduction in any medium, provided the original author(s) and source are credited.

\section{References}

1. Alexander LA, Link BG (2003) The impact of contact on stigmatizing attitudes toward people with mental illness. J Ment Health 3:271-289

2. Allport G (1954) The nature of prejudice. Addison-Wesley Publishing Company, Inc., Reading, MA

3. Angermeyer MC, Matschinger H (1997) Social distance towards the mentally ill: results of representative surveys in the Federal Republic of Germany. Psychol Med 27:131-141

4. Angermeyer MC, Matschinger H, Corrigan P (2004) Familiarity with mental illness and social distance from people with schizophrenia and major depression: testing a model using data from a representative population survey. Schizophr Res 69:179_ 180

5. Angermeyer MC, Matschinger H (2005) Labeling-stereotypediscrimination: an investigation of the stigma process. Soc Psychiatry Psychiatr Epidemiol 40:391-395

6. Brockman J, D'Arcy C (1978) Correlated of attitudinal social distance toward the mentally ill: a review and re-survey. Soc Psychiatry 13:69-77

7. Brown R, Zagefka H (2005) Ingroup affiliation and prejudice. In: Dovidio JF, Glick P, Budman LA (eds) On the nature of prejudice: fifty years after Allport. Blackwell, Malden, MA, pp 5470

8. Corrigan PW, Watson AC (2004) Stigma and public education about mental illness. Psychiatr Serv 55:834-835

9. Corrigan PW, Green A, Lundin R, Kubiak MA, Penn DL (2001) Familiarity with and social distance from people who have serious mental illness. Psychiatr Serv 7:953-956

10. Conner KO, Carr Copeland V, Grote N, Koeske G, Rosen D, Reynolds C, Brown C (2009) Mental health treatment seeking among older adults with depression: the impact of stigma and race. Am J Geriatr Psychiatry (under review)

11. Couture SM, Penn DL (2003) Interpersonal contact and the stigma of mental illness: a review of the literature. J Ment Health 3:291-305

12. González-Torres MA, Oraa R et al (2007) Stigma and discrimination towards people with schizophrenia and their family members. Soc Psychiatry Psychiatr Epidemiol 42:14-23

13. Kessler RC, Chiu WT, Demler O, Walters EE (2005) Prevalence, severity, and comorbidity of twelve months DSM-IV disorders in the National Comorbidity Survey Replication (NCS-R). Arch Gen Psychiatry 6:617-627

14. Lawrie SM (1999) Stigmatization of psychiatric disorder. Psychiatr Bull 3:129-131

15. Link BG, Cullen FT (1986) Contact with the mentally ill and perceptions of how dangerous they are. J Health Soc Behav 27:289-302

16. Link BG, Phelan JC (2001) Conceptualizing stigma. Annu Rev Sociol 27:363-385

17. Link BG, Struening EL, Neese-Todd S, Asmussen S, Phelan JC (2001) Stigma as a barrier to recovery: the consequences of stigma for the self-esteem of people with mental illnesses. Psychiatr Serv 52:1621-1626

18. Page S (1995) Effects of the mental illness label in 1993: acceptance and rejection in the community. J Health Soc Policy 2:61-80

19. Perlick DA, Roeseheck RA, Clarkin JF, Sirey J, Salahi J, Struening EL, Link BG (2001) Stigma as a barrier to recovery: adverse effects of perceived stigma on social adaptation of persons diagnosed with bipolar affective disorder. Psychiatr Serv 52(12): 1627-1632

20. Phelan JC (2005) Geneticization of deviant behavior and consequences for stigma: the case of mental illness. J Health Soc Behav 46(4):307-322

21. Phelan JC, Link BG (2004) Fear of people with mental illnesses: the role of personal and impersonal contact and exposure to threat or harm. J Health Soc Behav 45(1):68-80

22. Phelan JC, Bromet EJ, Link BG (1998) Psychiatric illness and family stigma. Schizophr Bull 24:115-126

23. Research Triangle Institute (2004) SUDAAN user's manual: Release 9.0. Research Triangle Institute, Research Triangle Park, NC

24. Ritsher JB, Phelan JC (2004) Internalized stigma predicts erosion of morale among psychiatric outpatients. Psychiatr Res 129:257265

25. Sirey J, Bruce M, Alexopoulos GS, Perlick DA, Friedman SJ, Meyers BS (2001) Stigma as a barrier to recovery: perceived stigma and patient-rated severity of illness as predictors of antidepressant drug adherence. Psychiatr Serv 52(12):1615-1620

26. Snow D, Anderson L (1987) Identity work among the homeless: the verbal construction and avowal of personal identities. Am J Sociol 92:1336-1371

27. Tajfel H (1970) Experiments in intergroup discrimination. Sci Am 223:96-102

28. Van't Veer JTB, Kraan HF et al (2006) Determinants that shape public attitudes towards the mentally ill. Soc Psychiatry Psychiatr Epidemiol 41:310-317

29. Wahl OF, Harman CR (1989) Family views of stigma. Schizophr Bull 15:131-139 